\title{
Educación Intercultural Bilingüe y Pensamiento Indigenista Aportes para un análisis Político
}

\section{Rolando Poblete Melis \\ Grupo Elima UAB \\ Introducción}

La educación intercultural es uno de los temas educativos que más interés ha despertado en los últimos años, pasando a ser dominio de numerosas disciplinas e investigadores que interesados en su desarrollo, se aproximan al tema desde diversas perspectivas; políticas, educativas, antropológicas y sociológicas, por nombrar solo algunas.

La razón de tal "amplitud de miras" se sustenta en que la educación intercultural abre la comprensión hacia asuntos tan importantes como la construcción de ciudadanía, los procesos de inclusión-exclusión social, ciertamente problemas educativos, y también, radicando allí su contingencia, racismo, xenofobia, discriminación, inmigración y minorías sociales. Precisamente, los aportes de ésta a la superación de tales conductas y actitudes son determinantes; primero porque facilita la aceptación de la diversidad, valorando la diferencia (mas no la desigualdad), y segundo, porque compromete al colectivo social en la construcción de relaciones más solidarias y democráticas donde todas las miradas tienen cabida, en un marco de respeto y comprensión mutua: esos son los objetivos hacia los cuales se debieran orientar todos los procesos educativos que se hacen llamar interculturales.

Por tanto, además del interés que de por sí genera el estudio de iniciativas educativas abiertas a la diversidad, se suma a ello el valor que otorga su actualidad, en tanto camino preciso que aporta a la solución de las trabas sociales que nacen de un mundo cada vez más interrelacionado; donde los movimientos migratorios son una constante mas que una excepción y donde las así llamadas minorías sociales (grupos étnicos, raciales, de clase, género, etc.), han adquirido mayor visibilidad, demandando sus derechos políticos al interior de los estados nacionales.

Curiosa tendencia que contradice la consolidada globalización y la progresiva homogeneización a la que ésta se encamina. En rigor, si hay algo que podemos afirmar con seguridad, es que los movimientos étnicos o nacionales (e incluso los grupos minoritarios), han adquirido una insospechada vigencia en diversos lugares del planeta, reclamando en algunos casos la independencia de estados y sociedades mayores; mientras que en otros la lucha se orienta hacia el reconocimiento de la 
autonomía territorial, política y cultural, como sucede con las étnias indígenas latinoamericanas.

Sea de ello lo que fuere, lo cierto es que cada vez se hace más patente la presencia de colectivos diversos en espacios sociales concretos reivindicando el derecho a su identidad y al ejercicio de una ciudadanía activa, situación que de alguna forma u otra impele a los estados a hacerse cargo de las situaciones y conflictos que ello pudiese generar, para garantizar en todo momento la gobernabilidad y también la satisfacción de aquellas demandas que son de su competencia.

En Latinoamérica, la situación política de las minorías indígenas ha posibilitado, generalmente desde el conflicto y el planteamiento de justas reivindicaciones, el nacimiento de lo que institucionalmente se conoce como educación intercultural bilingüe o educación bilingüe intercultural (según donde se ubiquen los énfasis) $)^{1}$.

La evolución de esta modalidad se inserta y corre paralela a lo que se ha dado en llamar el "pensamiento indigenista", por un lado, y los movimientos de reivindicación que buscan poner de relieve en el debate nacional la situación específica de tales grupos, por otro.

En lo que sigue, me interesa discutir algunos puntos que dicen relación con la educación intercultural y su funcionamiento al interior de los Estados nacionales, desde una mirada eminentemente política, para, en un segundo momento, exponer la periodización teórica y práctica que es posible realizar en torno al proceso de institucionalización de esta opción educativa en Latinoamérica. En tal sentido, el análisis transita por las diversas corrientes de pensamiento presentes en la historia latinoamericana reciente para abordar la "cuestión indígena", a saber, el indigenismo integracionista, el etnodesarrollo y finalmente el pensamiento autonómico.

\footnotetext{
${ }^{1}$ Estos son los dos términos oficialmente utilizados en Latinoamérica, a excepción de Colombia que denomina Etnoeducación a tales procesos. Por otro lado, la unión de conceptos (intercultural y bilingüe), responde a la intención de promover relaciones de doble vía entre un grupo blanco y los grupos indígenas minoritarios (en razón de su marginalidad y no necesariamente de su número), y el trabajo con las lenguas vernáculas de ellos y su utilización en espacios formales como la escuela.
} 


\section{Educación Intercultural en el marco del Estado Nación: Política y Ciudadanía}

Existe un hecho indiscutible, cual es la estrecha relación entre educación escolar (en tanto proceso de formación institucionalizado), los discursos políticos y los contextos dentro de los cuales éstos cobran sentido; dado que la educación es uno de los sectores donde claramente la intervención propia de los Estados es más explícita, no se puede dejar de establecer la conexión necesaria entre política y educación, relación a la cual se debe agregar un término más, el espacio social dentro del cual esos discursos adquieren actualidad. Precisamente, la misión educativa es organizar el contexto, entendido éste como ambiente total que incluye a grupos diversos dentro del tejido social, para la formación-asimilación de esa población en los principios y normas que rigen al colectivo.

La educación intercultural tampoco está al margen de tal constatación, por el contrario, la amplia en orden a reafirmar la ligazón que existe entre los extremos de una situación siempre evidente. Si la educación intercultural ha pasado a formar parte del discurso pedagógico oficial en los numerosos países que intentan aplicarla, es porque de alguna forma u otra el contexto social, es decir, la diversidad, se ha impuesto como una realidad ineludible para los Estados que ven en esta modalidad educativa la forma precisa de enfrentarla y controlarla.

Sin ir más lejos, es posible afirmar que la progresiva institucionalización de la educación intercultural y las normativas que la rigen en diversos Estados nacionales, son producto de situaciones políticas concretas que, con mayor o menor fuerza, han determinado su inclusión dentro de los sistemas educativos de países que han debido hacerse cargo de los problemas relativos a la inmigración o la presencia de minorías que expresaron sus demandas y justas reivindicaciones.

Para corroborar lo que afirmo basta revisar la historia del nacimiento de la educación intercultural o multicultural en contextos sociales precisos. Ello nos demostrará que en todos los países donde actualmente ésta se ha implementado, se han desarrollado hechos que dicen relación con la irrupción y presión en la vida pública de grupos inmigrantes y minorías sociales que, no aceptando la homogeneización que define las iniciativas generales (políticas sociales) y educacionales de los Estados, han comenzado a exigir la inclusión de su historia, experiencias y valoraciones en los procesos de socialización y escolarización. 
Si bien la educación intercultural es una necesaria reivindicación de grupos sociales diversos frente a los problemas de rendimiento escolar, los problemas de adaptación, marginación, exclusión social, desvalorización y discriminación al interior de la sociedad, demandas acompañadas por luchas y movilizaciones, el que se haya institucionalizado demuestra que para los Estados nacionales es una necesidad "controlar" un conflicto que puede ser mayor porque sus alcances son políticos, económicos y sociales. Por tanto, la educación intercultural se movería en un espacio fronterizo entre aquello que los grupos minoritarios entienden que es una reivindicación para acceder en forma igualitaria a la vida social y política de la sociedad, y por otra parte, entre aquellas acciones de control social que los Estados inevitablemente ejercen para mantener un orden que reduzca las posibilidades reales de cualquier tipo de conflicto que amenace los "intereses superiores" del Estado nación, es decir, la misma gobernabilidad. Esta es una tensión permanente que impide calificar la educación intercultural, y cualquier iniciativa estatal, como pura y exclusiva reivindicación o como solamente control.

Al enmarcar la educación intercultural o multicultural dentro de un sistema mayor de acciones intencionadas que se ejecutan para satisfacer una necesidad, otorgándole el estatuto de política social, resulta inevitable hacer patente esa tensión que se mueve entre ambas dimensiones, esto es, el control y la respuesta a esa demanda. Este es un hecho común dentro del proceder del Estado, porque todas las políticas (no sólo las educativas), destinadas a responder a problemas de grupos concretos $y$ en ámbitos diversos, mantienen y prolongan esa suerte de indeterminación que es funcional y útil a los extremos de la tensión: es la necesaria construcción de hegemonía lo que empuja a los programas oficiales -que seguirán siendo de los intereses dominantes- a atender e incluir, en espacios acotados y objetivos, las demandas e iniciativas que expresan a las clases subordinadas (Palma, 1998). En ese sentido, es control porque para el Estado existe un hecho primordial, que es asegurar la gobernabilidad, para lo cual se institucionaliza esa demanda para responder eficientemente a ella. Pero también es reivindicación porque representa la legítima aspiración de quienes han sido históricamente marginados y su inclusión dentro del aparato estatal, lo que de alguna forma garantiza la adquisición de una cierta "visibilidad" social.

Lo importante de todo esto es hacer constar que no es posible entender la educación intercultural sólo como el triunfo de un sector de la sociedad que lucha por 
justas demandas que apelan a su inclusión dentro del colectivo -para permitir desde la equidad educativa mejores rendimientos y también respeto por las manifestaciones culturales propias- sino también se debe considerar que para el Estado responder a la demanda de un grupo determinado es asegurar una forma de regulación y control, lo cual en última instancia nos muestra que el poder no es atributo únicamente de un aparato burocrático institucional. El poder, precisamente, al imponer límites, abre la posibilidad a un contrapoder que es resistencia y transgresión, y tal tensión es su dinámica.

Inevitablemente, al adentrarnos en ese plano nos ubicamos en un tema central, cual es la relación que establece el Estado con los grupos subordinados y las acciones que dirige hacia aquéllos, además, de las posibilidades reales de actuar que tienen estos grupos en el marco regulador que el Estado instaura. Situados en este último ámbito, es importante asumir que se abren espacios en los cuales las organizaciones populares o los grupos subordinados más conscientes (minorías, etnias, etc.), pueden ensayar formas alternativas para el uso de los recursos estatales, lo cual, en última instancia muestra que no todo lo que hacen los grupos populares es expresión de la subordinación, es decir, cada grupo concreto es portador de percepciones y capacidades aprendidas y elaboradas en su experiencia que no corresponden necesariamente a las enseñanzas de la dominación, sino que expresan sus propios esfuerzos por construir un mundo de vida que los interprete adecuadamente.

Afirmar el potencial de cambio real de las iniciativas estatales, sistematizadas y ordenadas en políticas sociales, pareciera contradictorio con la lógica bajo la cual funciona el Estado, porque ellas parecen más bien encaminadas a fortalecer la reproducción dado que son impulsadas en una línea de control social que se instala como el objetivo central de la política. Pero en función de lo expresado anteriormente, en relación a las capacidades de los grupos subordinados, existen espacios e iniciativas (aun en lo estatal) en que se puede propender a la constitución y fortalecimiento de sujetos colectivos, donde los participantes e involucrados ejercitan y desarrollan la asociatividad, iniciativa, conciencia y responsabilidad social. La educación práctica de los sujetos colectivos (autores responsables de la transformación de su propia realidad), es el rendimiento que pueden entregar las políticas sociales, y esa capacidad es condición necesaria para emprender cualquier cambio en la sociedad (Palma, 1998). 
Todo ello es especialmente importante para lo referido a la educación intercultural. Porque si bien es una iniciativa ordenada institucionalmente desde el Estado, abre el camino a la constitución y fortalecimiento de sujetos activos y conscientes capaces de modificar su realidad inmediata. Es decir, la educación intercultural es una posibilidad cierta para lograr el empoderamiento de los grupos minoritarios en orden a las transformaciones sociales que garanticen su inclusión igualitaria, como sujetos de derechos, en la sociedad. La participación que permite la educación intercultural encamina hacia la consolidación de sujetos colectivos, desarrollando en ese camino identidad de grupo y profundizando ciudadanía.

La educación intercultural adquiere mayor importancia en este nuevo escenario social y político, porque desde el rescate de las particularidades y especificidades de los grupos que entran en articulación en un proceso común, permite el encuentro de diversidades constructoras de sentido y realidad a través de la comunicación. Al dar cabida a las expresiones culturales se está dando un paso en el reconocimiento positivo de las identidades, facilitando el empoderamiento de grupos sociales para desde una perspectiva crítica aportar a la construcción de una sociedad más democrática y solidaria que reivindique la diferencia en un marco de igualdad social, política y económica. Pero a la vez, esta nueva modalidad educativa se inscribe dentro de un paradigma holístico que no sólo apela a la valoración de las diferencias, sino también a la promoción de aquellas habilidades precisas que permiten a los alumnos desenvolverse y responder adecuadamente a las exigencias de un mundo que valora por sobre todo la información y el conocimiento.

El proceso de institucionalización progresivo que caracteriza el avance no sólo de la educación intercultural, sino también de aquellas políticas sociales que rescatan la diferencia para valorizarla y otorgarle un grado de mayor visibilidad social, cobran sentido y especificidad en el marco del Estado nación, con todas las regulaciones y ordenamientos burocráticos que ello supone, representando uno de los extremos de la tensión antes mencionada entre la demanda y su satisfacción.

Puestos en el lugar de la demanda, es decir, la reivindicación, es obligación hacer referencia al contexto social y político dentro del cual ésta tiene cabida, porque las movilizaciones en orden a proponer modificaciones en las formas tradicionales de enfrentar el tema de la diferencia en educación, remiten invariablemente a un contexto claro y preciso caracterizado en algunos casos por un clima de conflicto y desagrado social en el cual, aquellos colectivos denominados minoritarios generalmente aliados 
con otros grupos progresistas, han comenzado a ejercer grados ascendentes de presión para hacer evidente su malestar.

En Latinoamérica, aunque nace al alero de la institucionalidad de los Estados, la educación intercultural bilingüe se liga fundamentalmente a un movimiento de repensamiento global sobre el rol de los indígenas en los Estados nacionales donde éstos habitan y las luchas por lograr su inclusión en un marco de respeto a sus culturas ancestrales, me refiero al movimiento indigenista, proceso que se aborda a continuación.

\section{Hacia una definición de "lo indígena"}

En Latinoamérica existe un vínculo definitivo entre la educación intercultural bilingüe y lo que se ha dado en llamar el pensamiento indigenista, entendido éste como la reflexión criolla y mestiza sobre el indígena, que ha cristalizado en numerosas políticas de acción dirigidas a los grupos étnicos del continente, por un lado, y entre los movimientos de reivindicación que buscan poner de relieve en el debate nacional la situación específica de los indígenas, por otro.

La educación intercultural bilingüe se ubica, entonces, en ese espacio que queda delimitado por el movimiento de reivindicación indígena y el pensamiento indigenista, en tanto respuesta institucionalizada a tal problemática. Por tanto, es preciso realizar un breve análisis de la evolución de esa tensión y conocer cuáles han sido las ideas que finalmente han dado origen y cabida en el marco de los Estados nacionales del continente a la modalidad educativa en cuestión.

Un primer tema que exige nuestra atención es delimitar claramente qué se entiende por indígena, porque dicho concepto justifica todas las intervenciones que se realizan tomando en cuenta tal condición en tanto categoría social. En el desarrollo del pensamiento indigenista institucionalizado ha existido un amplio abanico de definiciones acerca del término que nos ocupa (Huenchuan, 2002), la mayoría de ellas superadas y desechadas por insuficientes y porque no dan cuenta cabal de la cualidad específica que supone lo indígena. Criterios biológicos, lingüísticos y culturales resultan poco acertados a la hora de definir y comprender el desarrollo de las étnias en Latinoamérica.

En primer lugar, lo biológico remite a precisiones raciales que implican que aquello que distingue al indígena del resto de la población es su raza, sin embargo, la realidad de los indígenas latinoamericanos es cercana al mestizaje biológico y cultural, 
de manera que no existiría esa "pureza racial" que nos permita hablar de éstos como grupo aparte y distinto.

Los mismo ocurre con el criterio lingüístico, porque obligados a vivir en una sociedad que no es la propia y ha desenvolverse adecuadamente en ella, los indígenas han abandonado su lengua de origen y han asumido, en algunos casos, el bilingüismo, mientras que en otros hay comunidades donde los idiomas vernáculos están en proceso de perderse definitivamente porque las nuevas generaciones han adoptado como lengua primera aquella que caracteriza a la sociedad mayoritaria.

Por último, lo referido a la cultura tampoco facilita la comprensión total de la complejidad que implica lo indígena, porque gran parte de las comunidades, si no todas, han adquirido elementos occidentales que han incorporado en su quehacer cotidiano, estableciéndose una suerte de "mestizaje cultural".

Si se ha propuesto que las categorías raciales, lingüísticas y culturales resultan insuficientes para comprender la especificidad indígena, debiéramos aceptar que ésta se define más bien por otras consideraciones que apuntan hacia su aspecto político. En efecto, "indígena no es una condición en sí-como nos dice Bonfil-, sino una relación entre Pueblos y Estados,-como nos dice Toledo-, siendo, por tanto, una categoría política."2

De lo que se trata es de afirmar que la especificidad de lo indígena viene dada por una relación que se establece entre un pueblo originario y el Estado dentro del cual éste existe. Huenchuan $(2002)^{3}$ cita un texto de Toledo que expresa esta situación:

\begin{abstract}
"Un pueblo originario es convertido en indígena en tanto ha sido colonizado y marginalizado por un Estado nacional, y en tal proceso han sido conculcados sus derechos colectivos que le son inherentes como pueblo: al control de su propio desarrollo cultural, lingüístico, económico y político, en su territorio ancestral."
\end{abstract}

Por tanto, la condición de indígena es un proceso que se ha constituido desde la colonia misma, momento en que un grupo blanco y criollo pasa a ocupar una posición privilegiada en desmedro del otro: los indígenas. Tal situación ha

\footnotetext{
${ }^{2}$ Huenchuan, C. (2002) El Pensamiento Indigenista Mexicano. Desde la Revolución Mexicana al Levantamiento Zapatista en Chiapas. Revista América Latina, 2, 121-165, pág. 125.

${ }^{3}$ Op. Cit. pág, 125.
} 
desencadenado el desarrollo de una historia plena de desigualdades que han caracterizado la vida de los grupos étnicos. De hecho los procesos de marginalización de las étnias de la vida nacional tienen su origen en el descubrimiento y conquista de América cuando una cultura se superpone a la otra. Sin embargo, esta situación de marginación lejos de disminuir o superarse con la llegada de la independencia en los numerosos países del continente, determinando el nacimiento de los primeros Estados nacionales, se acentúa todavía más, porque "el Estado liberal nacido a imitación de su homónimo europeo, ante la necesidad de resolver el dilema civilización o barbarie, prefirió la marginación y exclusión de las étnias renunciando a su pretendida integración y apostando a la progresiva extinción de sus lenguas," ${ }^{4}$ aunque tal exclusión opera en ámbitos más amplios y dramáticos que lo puramente lingüístico.

La tradición liberal en la cual se sustentan los nuevos Estados nacionales condujo inevitablemente a la negación de la personalidad política propia de los pueblos indios (Bonfil, 1982). Los resultados de tal situación fueron catastróficos, porque "la independencia política de los Estados latinoamericanos no corrigió, en lo interno, muchos de los problemas básicos que acarreaban los pueblos indios desde la instauración del régimen colonial, y en cambio sí generó una embestida en gran escala contra las tierras, las formas de organización y las identidades sociales de las comunidades étnicas." 5 Las consecuencias de todo ello no se hicieron esperar: disminución de la calidad de vida y empobrecimiento progresivo, marginación de los bienes y servicios que se ofrecían al resto de la población y por sobre todo, la negación de la presencia indígena en los espacios de poder y decisión, impidiendo avanzar hacia una sociedad más democrática y justa que se reconozca como multiétnica.

Esta situación ha sido compartida por la mayoría de los países de la región y denunciada permanentemente por los movimientos indígenas, que han buscado el reconocimiento de derechos en distintos sectores que podrían agruparse en el establecimiento de un estatuto político; el derecho a organización social; desarrollo económico y social autónomo; y el desarrollo lingüístico y cultural. ${ }^{6}$ Sin embargo,

\footnotetext{
${ }^{4}$ Barnach-Calbo, E. La Nueva Educación Indígena en Iberoamérica. Revista Iberoamericana de Educación, 13, 13-33, pág. 21.

${ }^{5}$ Bonfil, G. (1982) El Etnodesarrollo: Sus Premisas Jurídicas, Políticas y de Organización. En: Bonfil, G. et al. (1982) América Latina: Etnodesarrollo y Etnocidio. San José, FLACSO, 131145, pág. 137.

${ }^{6}$ Cfr. Barnach-Calbo, E. La Nueva Educación Indígena en Iberoamérica. Revista Iberoamericana de educación, 13, 13-33.
} 
llegar a tales exigencias ha sido un proceso paulatino que ha supuesto largas luchas desarrolladas a lo largo del siglo XX y el tránsito por apuestas teórico-políticas que han determinado las formas en que los Estados han enfrentado la cuestión indígena.

También, son un aspecto importante los modos específicos en que los mismos indígenas se han hecho sujetos de su propia historia para lograr aquellas transformaciones necesarias que garanticen su inclusión en la vida social y política de los Estados, en un marco de respeto a sus costumbres y territorios ancestrales. Por tanto, conocer la dimensión teórica y política que ha marcado las relaciones entre el Estado y los indígenas es una necesidad para situar adecuadamente en este contexto global la irrupción de la educación intercultural bilingüe.

\section{Las corrientes de pensamiento y los indígenas}

Durante el transcurso de los siglos XIX y XX los Estados nacionales enfrentaron de diversa forma las problemáticas nacidas de la cuestión indígena, siendo las principales corrientes aquellas que apelaban, en primer lugar, a la integración de éstos al resto de la sociedad, proceso conocido como indigenismo integracionista que en el fondo es exclusivamente asimilación; luego, durante el desarrollo del pensamiento marxista se suponía que los indígenas de una forma u otra debían constituir junto al campesinado un grupo de clase homogéneo que luchara por la superación liberadora de la estructura de dominación de clase, corriente denominada etnomarxismo; el etnodesarrollo, entendido como la ampliación y consolidación de los ámbitos de la cultura propia, mediante el fortalecimiento de la capacidad autónoma de una sociedad culturalmente diferenciada para guiar su propio desarrollo y el ejercicio de la autodeterminación (Bonfil, 1982), corriente nacida al alero del espacio académico, es la fase previa y antecedente en la constitución del pensamiento autonómico, que guiará el avance del movimiento indigenista más o menos desde los años noventa en adelante.

Si bien antes de la década del ochenta, década en que adquiere mayor fuerza el pensamiento ligado al etnodesarrollo, se tenía conocimiento de algunas iniciativas de trabajos ligadas a la educación bilingüe, es a partir de ese momento, y posteriormente en función del pensamiento autonómico, donde tiene cabida 
formalmente la educación intercultural bilingüe en tanto proceso educativo que busca potenciar la escolarización de los grupos étnicos en un marco de respeto a su cultura y su lengua. Desde ese momento, los Estados comienzan a hacerse cargo de la presión ejercida por los indígenas y organizaciones afines, proponiendo y organizando al interior de su institucionalidad esta modalidad educativa, modificando sus estructuras formativas tradicionalmente asimilacionistas. Un claro signo de ese cambio es que si bien ha sido una constante la falta de preocupación de los Estados por los pueblos originarios, es a partir de los años ochenta que esta situación tiende a modificarse, al menos así lo expresan las distintas constituciones políticas y cuerpos legales de numerosos países del continente que comienzan a "hacerse cargo" de esta nueva visibilidad social que adquiere lo indígena (Poblete, 2002).

\section{1 El movimiento integracionista: una forma más de asimilación}

El proceso de integración, conocido como indigenismo integracionista (Bonfil, 1987), se desarrolla en etapas diversas que determinan la forma de afrontar la presencia de los grupos étnicos al interior de los Estados nacionales del continente. Sin embargo, el rasgo común es ser consecuente con un proyecto global que busca el desarrollo modernizador político y económico de los países latinoamericanos.

No es de extrañar que para la concepción desarrollista se viera a los indígenas y sus culturas (formas de tenencia de la tierra, estructura social y política, religiones, lengua, etc.) como uno de los principales obstáculos para el objetivo mayor que ya se había trazado: el progreso. En efecto, se asumió que las verdaderas causas del subdesarrollo se encontraban en el atraso, el primitivismo y la falta de modernidad; pero también se asumió que quienes representaban y encarnaban esos obstáculos con total claridad eran precisamente los indígenas. Desde ese momento comienza a verse la diversidad como un problema al desarrollo, a la construcción nacional, a la modernización, al anhelado progreso (Bonfil, 1987). Las políticas que se llevan a cabo en ese momento tienen una clara finalidad: "lograr que los indios dejaran de ser indios mediante el sencillo expediente de cambiar su cultura por la cultura dominante. Se trataba de desindianizar estos países.... La cultura india, concebida siempre como 
inferior, debía ser substituida por otra cultura, la cultura dominante occidental y cristiana." ${ }^{7}$

En lo que concierne a las políticas educativas, las repercusiones de tales concepciones en el espacio escolar no se hicieron esperar. De hecho, la escuela es el gran instrumento "enculturador-aculturador" para lograr la pretendida integración. En ese sentido, históricamente los Estados han fijado políticas educacionales hacia los pueblos indígenas impositivas y excluyentes, coherentes con la realidad de los grupos pertenecientes a la cultura dominante, buscando la creación de una identidad nacional que no reconoce ni asume la condición pluriétnica de los países del continente, marginando de los planes y programas de estudio los contenidos que pudiesen considerar a las culturas originarias y la conservación de su patrimonio (Poblete, 2002).

Las naciones modernas en su afán por construir los ideales de unidad, confundido éste con uniformidad y homogeneidad, para avanzar en forma segura al desarrollo, "utilizan el proceso de enseñanza-aprendizaje como instrumento, no para educarse y construir conocimientos, sino como substituto de las armas para el etnocidio o la evangelización y se pretende que, por medio de la educación, desaparezca la identidad étnica y lingüística, como si esta tuviera que ver con el proceso real de aprendizaje."

En el esfuerzo por eliminar la diversidad se acudió y se acude a métodos coercitivos y violentos: utilizar maestros que solo hablaran castellano (o portugués), cambiar la ropa de los niños que asisten a las escuelas, eliminar toda posibilidad de usar los recursos culturales propios e introducir los recursos de la cultura nacional que en el trasfondo representaban la continuidad del sistema colonial: Europa en América (Nahmad, 1982). Frente a tal realidad se han construido los procesos de enseñanzaaprendizaje en el continente, descartando otorgar algún matiz de visibilidad y participación a la diversidad cultural al interior de las aulas, como una forma válida y necesaria para la construcción no sólo de conocimientos sino de relaciones respetuosas de esa diversidad.

Debemos concluir que las políticas educativas han sido "centralistas y uniformadoras tendientes, aunque sin lograrlo, a una completa asimilación de las

\footnotetext{
${ }^{7}$ Bonfil, G. (1987) Los Pueblos Indios, sus Culturas y las Políticas Culturales. En: Canclini, N. Ed. (1987) Políticas Culturales en América Latina. México, Grijalbo, 88-125, pág. 91.

${ }^{8}$ Nahmad, S. (1982) Indoamérica y Educación: ¿Etnocidio o Etnodesarrollo? En: Bonfil, G. et al. (1982) América Latina: Etnodesarrollo y Etnocidio. San José, FLACSO, 161-182, pág. 166.
} 
poblaciones indígenas a la cultura nacional. El objetivo implícito ha sido la asimilación para lo cual se han utilizado numerosos mecanismos de dominación, siendo la escuela el instrumento fundamental de cambio."9

Las consecuencias que han generado en el ámbito educativo las políticas del indigenismo integracionista, apuntan al alejamiento y abandono del sistema educativo de los grupos étnicos, marginándose del proceso de avance del resto de la población, en unos casos, mientras que en otros la expresión de esa política se ha visto reflejada en bajos niveles de logros académicos. En efecto, en cuanto al abandono, sólo uno de cada dos niños indígenas logra terminar la primaria, y el promedio de repetición es del $20 \%$ al $30 \%$ de dicho nivel, concentrado en un $40 \%$ a $50 \%$ en el primer grado, la tasa más alta de cualquier región del mundo (Barnach-Calvo, 1997).

Bajo todo punto de vista las políticas integracionistas fueron y siguen siendo un verdadero fracaso, primero porque el modelo desarrollista que las inspiró colapsó y segundo porque potenciaron, sin quererlo, el nacimiento de las organizaciones políticas indígenas (organizaciones que bajo tal lógica debían desaparecer).

Esto significa que en un proceso constante los indígenas se han hecho sujetos de su propia historia, ampliando sus preocupaciones hacia ámbitos hasta entonces negados: la transformación social y política. Basta revisar las numerosas conferencias mundiales que desde los años setenta se vienen sucediendo y que ponen en el centro del debate las problemáticas indígenas, para comprobar que éstos han adquirido mayor visibilidad a nivel global. Las nuevas reivindicaciones territoriales, culturales, políticas, etc., comienzan a ser escuchadas por los Estados nacionales hasta esos momentos sordos a dichas demandas.

\section{2 Del Etnodesarrollo al Pensamiento Autonómico}

En ese marco surge el etnodesarrollo como alternativa a la integraciónasimilación indígena y al etnomarxismo, corriente que con un lenguaje diferente propone la formación de una clase social única compuesta por campesinos e indígenas: juntos deberán luchar por la transformación de aquellas estructuras económicas que reproducen las desigualdades. Se trata, una vez más, de lograr que los indígenas dejen de lado sus especificidades, pasando de una situación de casta a

\footnotetext{
${ }^{9}$ Supanta, A. (1995) La Ley Indígena y los Desafíos para Implementar una educación Intercultural Bilingüe en Chile. En: MINEDUC-CONADI (1995) Calidad, Identidad, Diversidad: Conversaciones sobre Educación Intercultural Bilingüe en Chile. Temuco, MINEDUC-CONADI, 17-22, pág. 17.
} 
una situación de clase (Bonfil, 1982). Sin embargo, la lucha de los Estados por hacer que los indios dejen de ser indios ha fracasado: las evidencias muestran que la mayoría de los grupos indígenas latinoamericanos han empezado a participar activamente en los procesos de transformación social, adquiriendo en muchos Estados grados de protagonismo que para las clases dominantes-blancas resulta peligroso: ejemplos paradigmáticos son el levantamiento indígena del Ecuador de 1990, la Marcha por el Territorio y la Dignidad de los Pueblos indígenas en Bolivia el año 1991 y el reciente movimiento de protesta que terminó con la renuncia del presidente en ejercicio, la irrupción del EZLN en México y las movilizaciones mapuches por la mayor participación y la recuperación de sus tierras ancestrales en el sur de Chile, conflicto evidentemente violento.

El etnodesarrollo, concepto propuesto en el marco de una reunión técnica internacional convocada por UNESCO y FLACSO en diciembre del año 1981 en San José de Costa Rica, es definido como:

"Entendemos por etnodesarrollo la ampliación y consolidación de los ámbitos de cultura propia, mediante el fortalecimiento de la capacidad autónoma de decisión de una sociedad culturalmente diferenciada para guiar su propio desarrollo y el ejercicio de la autodeterminación, cualquiera que sea el nivel que considere, e implican una organización equitativa y propia del poder. Esto significa que el grupo étnico es la unidad político-administrativa con autoridad sobre su propio territorio y capacidad de decisión en los ámbitos que constituyen su proyecto de desarrollo dentro de un proceso creciente de autonomía y autogestión."10

En la definición propuesta, hay algunos términos que requieren ser aclarados, sin embargo, pienso que la mayor complejidad se presenta a la hora de enfrentar el tema del ejercicio de la autodeterminación o régimen de autonomía, fundamentalmente porque ésta es la tendencia que se viene imponiendo en el debate más o menos desde los inicios de la década del noventa y representa una clara superación de las formas tradicionales del pensamiento indigenista, esto es, la integración y el etnomarxismo.

\footnotetext{
${ }^{10}$ Cfr. Declaración de San José, en Bonfil, G. et al. (1982) América Latina: Etnodesarrollo y Etnocidio. San José, FLACSO.
} 
La autonomía representa un campo que organiza y dota de sentido comprehensivo a todas las reivindicaciones de los pueblos indígenas (Huenchuan, 2002). De esta forma, las demandas actuales se ordenan bajo aquel paradigma que básicamente, según la misma autora, se refiere a un régimen especial que configura un gobierno propio (autogobierno) para ciertas comunidades [o regiones] integrantes, las cuales escogen así sus autoridades que son parte de la colectividad, ejercen competencias legalmente atribuidas y tienen facultades mínimas para legislar acerca de su vida interna y para la administración de sus asuntos. ${ }^{11}$

Los elementos constitutivos del régimen de autonomía son en primer lugar el territorio, es decir, no sólo tierras para la producción sino un espacio dentro del cual desplazarse libremente, luego, un estatuto legal que otorgue legitimidad jurídica dentro del juego legalista de los Estados nacionales, derivándose de este derecho el de autonomía política y finalmente los derechos lingüísticos y culturales (Varese, 1982).

No cabe duda que las propuestas autonómicas han encontrado detractores en el seno de los Estados nacionales, donde grupos de intereses económicos aún sostienen la necesidad de la integración de los indígenas para optar al desarrollo y progreso común, sin embargo, son los propios grupos étnicos quienes ven en la autonomía la única y real posibilidad de avanzar hacia un verdadero crecimiento dentro de los países donde existen, proceso que se ha visto potenciado por el establecimiento del régimen de autonomía en las regiones norte y sur de la Costa Atlántica del Caribe, llevado a cabo por la Nicaragua Sandinista en 1987 y, el levantamiento del Ejército Zapatista de Liberación Nacional que ha terminado por legitimar al interior de las organizaciones indígenas la voluntad de luchar por sus derechos políticos, económicos y culturales, para alcanzar visibilidad social, en un marco de respeto a sus tradiciones ancestrales.

Lo cierto es que, como se mencionó anteriormente, los indígenas han buscado el reconocimiento de sus derechos en cuatro sectores fundamentales: el establecimiento de un estatuto político; el derecho a organización social; desarrollo económico y social autónomo y finalmente el desarrollo lingüístico y cultural. Sea de ello lo que fuere, es importante hacer constar que la educación intercultural bilingüe se inscribe en esta nueva perspectiva que busca potenciar los ámbitos de la cultura propia en comunicación y apertura con aquellos aspectos específicos de la cultura

\footnotetext{
${ }^{11}$ Cfr. Huenchuan, S. (2002) El Pensamiento Indigenista Mexicano. Desde la Revolución Mexicana al Levantamiento Zapatista en Chiapas. Revista América Latina, 1, 121-165.
} 
occidental de los países del continente (interculturalidad), ello, mediado por la utilización de la lengua vernácula y la incorporación del castellano como segundo idioma (bilingüismo).

\section{La Educación Intercultural Bilingüe y su irrupción al interior de los Estados Nacionales}

En cuanto a la implementación de la EIB, históricamente podemos situar las primeras experiencias cercanas a tal modalidad en la década del sesenta, e incluso antes, cuando maestros indígenas de Ecuador, Perú, Bolivia y México, en los años treinta, plantearon algunas iniciativas autogestionadas que apuntaban en lo general al rescate de las culturas y lenguas autóctonas. Obviamente, los estados mostraron escaso interés por tales actividades condenándolas a la desaparición por falta de apoyo de todo tipo (Barnach-Calvo, 1997). También, y en forma previa a la aplicación de la educación intercultural bilingüe, se puede decir que el concepto de biculturalidad precedió al de interculturalidad. Se sabe que tales iniciativas respondían a los intentos asimilacionistas que pretendían ser funcionales al fin integrador. El supuesto de la educación bicultural y bilingüe es que si era posible adquirir dos sistemas lingüísticos, era igualmente posible adquirir dos sistemas culturales. Pero, "el matiz importante era que si la lengua materna se usaba como puente para pasar a la lengua mayoritaria, también la cultura propia permitiría el tránsito a la cultura mayor."12

Sin embargo, es a partir de los años ochenta, en el marco de la coyuntura teórica y política derivada del etnodesarrollo y con mayor fuerza de las ideas autonómicas, que esta situación tiende a cambiar, al menos así lo expresan las distintas constituciones políticas y cuerpos legales que se han puesto en marcha en numerosos países latinoamericanos. En esta nueva visión, el concepto de interculturalidad parte del reconocimiento de la diversidad (histórica, cultural, lingüística, ecológica, etc.), ya no como barrera sino como recurso (Moya, 1998). La orientación final puso los énfasis en las condiciones subalternas de los pueblos indígenas, privilegiando en algunos casos la importancia de la lengua, aunque sin dejar de lado lo intercultural (por ejemplo en Guatemala se llama Educación Bilingüe Intercultural) y en otros las relaciones simétricas entre los grupos indígenas y la sociedad mayoritaria (Educación Intercultural Bilingüe, como el caso de Chile que

\footnotetext{
${ }^{12}$ Moya, R. (1998) Reformas Educativas e Interculturalidad en América Latina. Revista Iberoamericana de Educación, 17, 105-187, pág. 109.
} 
restringe el uso de los idiomas vernáculos a aquellas zonas de alta concentración indígena e instaura a nivel nacional una unidad temática que recoja los contenidos propios de la interculturalidad). Lo cierto es que muchos de los Estados donde la población étnica es considerable, han implementado o señalado apartados dentro de sus constituciones que tienden al reconocimiento de derechos (aunque no en los términos absolutos que exigen los indígenas), para los pueblos originarios que buscan mantener sus lenguas vernáculas e incluso utilizarlas en los proceso educativos.

En todos los países donde han comenzado a visualizarse tales cambios, el idioma oficial es el español, posibilitándose el uso de las lenguas vernáculas, así, por ejemplo, se considera formando parte de la cultura nacional el Quichua y demás lenguas aborígenes en Ecuador; lo mismo ocurre con las lenguas autóctonas en El Salvador. En Perú (1993) también es oficial el uso en las zonas donde predominen el Quechua, el Aymará y otras lenguas según la ley. La constitución colombiana (1991) establece que las lenguas y dialectos de los grupos étnicos son también oficiales en sus territorios, lo mismo la nicaragüense que estipula que los idiomas de las comunidades atlánticas también tendrán uso oficial en los casos que establezca la ley. En Guatemala (1985), se establece que la educación podrá impartirse en forma bilingüe en aquellas escuelas ubicadas en zonas indígenas (en rigor, esto es en casi todo el país). Desde 1992 el Guaraní cuenta con reconocimiento oficial en el Paraguay. Argentina, en un artículo de la constitución reformada de 1994 reconoce la preexistencia étnica de los pueblos indígenas y consagra el derecho a una EIB. Lo mismo ocurre en Bolivia según la constitución de 1994. La ley indígena chilena (1993) también establece el derecho a una EIB en las zonas de alta concentración indígena, mientras que en México y gracias al trabajo reivindicativo del EZLN, a partir de 1996 se han establecido como prioritarias las reformas a la constitución tendientes a la creación de regiones autónomas pluriétnicas. ${ }^{13}$ En resumen, son once países los que han reconocido en sus constituciones el derecho a una educación en lengua propia, mientras que el resto de países (Chile entre ellos), han propuesto un número significativo de leyes y decretos que consagran tal derecho (López y Küper, 1999).

Al menos en lo que se refiere a cuerpos legales, la EIB tiene un estatuto en la mayoría de los países de la región, lo que sin embargo, no garantiza bajo ningún respecto su aplicación y establecimiento. Es por eso, que existe una permanente

${ }^{13}$ Cfr. Barnach-Calbo, E. La Nueva Educación Indígena en Iberoamérica. Revista Iberoamericana de Educación, 13, 13-33. 
preocupación de los grupos indígenas organizados en torno a la consecución de sus reivindicaciones, potenciado todo ello por la permanente atención de organismos internacionales en los procesos de cada uno de los países comprometidos con tales cambios.

En cuanto a las significaciones que el desarrollo de la EIB implica para las comunidades indígenas, se puede sostener que ésta representa mucho más que una necesidad educativa, es también una justa retribución a los años de postergación, marginación y exclusión de la vida nacional. Para los pensadores indígenas, la EIB es "el espacio privilegiado para construir un proyecto descolonizador de los pueblos que permita pasar de la exclusión de las lenguas y culturas indígenas, a una situación de inclusión; de la proscripción de los sistemas de creencias profanas y sagradas pasar a la aceptación mutua en la convivencia con la cultura nacional de corte occidental. Relegitimar y represtigiar a las culturas indígenas se constituye así en una finalidad de la EIB al tiempo que la continuidad y recreación cultural se constituye en dos de sus objetivos específicos." ${ }^{\text {14 }}$

Según la percepción de los indígenas, la opción transformadora que entrega la EIB debe ser considerada como un aporte para todo el conjunto de la sociedad, en la medida que es objeto de ésta humanizar las relaciones sociales y trabajar en la aceptación de las diferencias inherentes a los grupos humanos, y en especial en sociedades multiétnicas como las nuestras. Si bien para los grupos étnicos la EIB tiene un fuerte componente reivindicativo, existe coincidencia con los pensadores no indígenas en la necesidad de trabajar y potenciarla dada la posibilidad real y cierta de beneficiar al conjunto de la sociedad. Para unos y otros, el proceso de interculturalidad educativa requiere de enormes esfuerzos de transformación social: ello alude a los cambios que debemos vivir como sociedad con el fin de avanzar hacia la liberación de los prejuicios y la erradicación de todas las trabas sociales como el etnocentrismo, la represión, el totalitarismo, el racismo y la xenofobia, cambios que, sin duda, se ven facilitados por la instauración definitiva en el currículum de la EIB.

La educación intercultural bilingüe propone el desarrollo de los aprendizajes propios de las culturas originarias, incluyendo los aspectos y conocimientos de las culturas no indígenas. Se trata de buscar la apertura y permeabilización de ambas a modo de diálogo, no restringiendo ni limitando a los educandos en los ámbitos de sus

\footnotetext{
${ }^{14}$ Cañulef, E. (1998) Introducción a la Educación Intercultural Bilingüe en Chile. Temuco, Instituto de Estudios Indígenas-UFRO, pág. 238.
} 
culturas propias. Esta modalidad busca reafirmar la identidad étnica de los alumnos indígenas evitando la situación de menoscabo cultural generado desde los planes habituales de estudio, para promover las manifestaciones propias de cada etnia, en un marco de respeto a los idiomas originarios en tanto expresión primera de ellos. El esfuerzo es lograr que los alumnos se perciban efectivamente como diferentes (no desiguales), pero en un país que acoge y valora tales diferencias. Dos son, obviamente, los conceptos centrales a partir de los cuales se ubican los énfasis: lo intercultural y lo bilingüe, ambos en una relación de mutua dependencia.

El primero de ellos alude a la necesidad de buscar una relación curricular que se establece entre los saberes, conocimientos y valores propios o apropiados de las sociedades indígenas y aquellos desconocidos y ajenos, además de la búsqueda de un diálogo y de una complementariedad permanente entre la cultura tradicional y aquella de corte occidental (López y Küper, 1999). En ese diálogo simétrico de culturas, es posible conseguir mejorías significativas de la autoestima de los alumnos indígenas, históricamente relegados a un segundo plano. De la aplicación de procesos de educación intercultural se debiera lograr que los educandos (indígenas y no indígenas) acepten sin temores su condición étnica y manifiesten actitudes positivas de respeto hacia sus orígenes; y aprendan a socializarse y vivir con las diferencias que implica el encuentro de seres diversos en el espacio escolar y social. Por eso, el énfasis del proceso está puesto en la identidad de los alumnos y la promoción de la autoestima, el trabajo con las diferencias culturales a partir de las expresiones propias de cada étnia, la sociedad nacional y, finalmente, el conocimiento de los aspectos más característicos de las culturas indígenas.

En cuanto a lo lingüístico, se dejan de lado los modelos transicionales, es decir, aquellos que guiaron las intervenciones educativas hacia los pueblos indígenas durante el período ideológico de asimilación, que incluían la educación bilingüe como modalidad compensatoria capaz de nivelar educativamente, en un plazo determinado, a la población indígena con la no indígena, de manera que la educación pudiera trasmitirse exclusivamente en el idioma hegemónico a partir del tercer o cuarto año (López y Küper, 1999). Bajo el paradigma de educación intercultural bilingüe, la lengua es trabajada a través de modelos de mantenimiento que tienden al desarrollo de los idiomas indígenas y la inclusión de la lengua hegemónica como segundo idioma: de esta forma, se promueve un bilingüismo aditivo. 
En lo referido exclusivamente a los contenidos, el consenso de los grupos indígenas expresado en la Declaración Indígena del II Congreso Latinoamericano de EIB, celebrado en Santa Cruz de la Sierra, Bolivia ${ }^{15}$, reconoce como ejes principales de la EIB, en primer lugar, la pedagogía bilingüe en los procesos de enseñanza aprendizaje; en segundo lugar, la cultural, la sociedad y la naturaleza, temas recogidos desde la perspectiva intercultural; y por último, la comunicación, que desarrolla temas propios del lenguaje como la lengua y el bilingüismo. Estos tres ejes cuya característica es la transversalidad, y a partir de los cuales debe ser puesto el énfasis en el trabajo educativo, constituyen los principales elementos que a nivel curricular debe afrontar la pedagogía intercultural y bilingüe. El primero de ellos alude a las innovaciones pedagógicas y metodológicas tendientes a favorecer los procesos de enseñanza aprendizaje al interior del aula, que para facilitar el bilingüismo, debieran promover la utilización por parte de los docentes de la lengua vernácula de los grupos indígenas. El segundo eje trabaja desde el rescate de los aspectos propios de las culturas que entran en articulación, cosmovisiones, tradiciones, etc., y el modo de integración de éstos en un mismo currículum. Finalmente, el tema comunicativo se refiere a la integración de la lengua vernácula y su complementación con el idioma oficial de la sociedad mayor.

Claramente, la consecución de los objetivos anteriormente señalados, requiere el desarrollo de metodologías participativas en que los alumnos se hagan protagonistas del proceso de enseñanza aprendizaje. Se trata, en definitiva, de lograr aprendizajes que apunten a la asociatividad e interdisciplinariedad. En la medida en que los aprendizajes se tornan significativos, valiosos y trascendentes para la propia vida y relación con el medio, se logra un grado de compromiso mayor con el proceso. Estos aprendizajes buscan que la persona enriquezca sus facultades comprensivas para desarrollar capacidades y talentos potenciales que tiendan a su relación social. Esto, a partir de la reflexión de lo cotidiano: el mundo propio de los niños entre en la escuela. Pero aquello que otorga el carácter intercultural, es que ese mundo se perciba y se acepte como diferente; de esa manera nos acercamos al respeto, a crecer con las diferencias y en la aceptación del otro. Resulta especialmente importante y pertinente la utilización de tales metodologías de trabajo para las comunidades indígenas, precisamente, porque éstas valoran sobremanera la construcción del conocimiento conjunto, participativo y relacionado con su mundo

${ }^{15}$ Cfr. Op. Cit. 
inmediato y circundante, donde tiene cabida la representación de la propia cosmovisión y las tradiciones.

\section{Consideraciones Finales}

En este trabajo me ha interesado abordar algunos elementos que apuntan a explicar la inevitable, y acaso necesaria, relación entre educación intercultural y política. El supuesto es que dado el carácter institucional que esta modalidad ha adquirido, en los últimos años y en todos los países que intentan aplicarla, se debe aceptar como correlato, el hecho que los Estados no son indiferentes a las situaciones que supone la presencia de grupos minoritarios al interior de sociedades complejas. Sin embargo, en esa tensión que se ubica entre la demanda y la satisfacción, la educación intercultural ofrece alternativas reales para el empoderamiento de tales grupos, logrando su integración en plenitud de derechos al funcionamiento social. Por otro lado, y pienso que esto es determinante, aun en los diferentes contextos donde se aplica, es fundamental que las sociedades mayores sean educadas en los principios democráticos y solidarios de la interculturalidad. En rigor no tiene sentido promover actitudes de aceptación en un grupo minoritario si el resto de la sociedad no ha desarrollado esa misma capacidad de aceptación. En tal sentido, los Estados y sus políticas tienen mucho que decir, además de voluntad política (nuestros gobiernos están llenos de "buena voluntad") se requiere de acciones precisas y eficientes en tal sentido.

Transitar por los antecedentes teóricos de la EIB en Latinoamérica es un ejercicio académico que puede extrapolarse a cualquier sociedad, porque con matices y diferencias, cualquier investigador podría descubrir antecedentes similares para casos particulares. Más allá de tal constatación, lo que me ha interesado ha sido dejar en claro el vínculo sólido que existe entre política y educación. La conclusión es que resulta indiscutible la relación de dependencia entre ambos extremos. Los procesos educativos son consecuencia lógica de una concepción acerca de la misión que al Estado le compete respecto de la finalidad de ésta. Esa concepción se compromete además, con una visión sobre el individuo y su rol en la sociedad, es decir, responde a la pregunta sobre qué clase de individuo se quiere formar y para qué.

\section{Bibliografía}


Barnach-Calbo, E. La Nueva Educación Indígena en Iberoamérica. Revista Iberoamericana de Educación, 13, 13-33.

Bonfil, G. (1982) El Etnodesarrollo: Sus Premisas Jurídicas, Políticas y de Organización. En: Bonfil, G. et al. (1982) América Latina: Etnodesarrollo y Etnocidio. San José, FLACSO, 131-145.

(1987) Los Pueblos Indios, sus Culturas y las Políticas Culturales. En: Canclini, N. Ed. (1987) Políticas Culturales en América Latina. México, Grijalbo, 88-125.

Cañulef, E. (1998) Introducción a la Educación Intercultural Bilingüe en Chile. Temuco, Instituto de Estudios Indígenas-UFRO.

Huenchuan, C. (2002). El Pensamiento Indigenista Mexicano. Desde la Revolución Mexicana al Levantamiento Zapatista en Chiapas. Revista América Latina, 1, 121-165.

López, L. y Küper, W. (1999) La Educación Intercultural Bilingüe en América Latina: balance y perspectivas. Revista Iberoamericana de Educación, 20, 17-85.

Moya, R. (1998) Reformas Educativas e Interculturalidad en América Latina. Revista Iberoamericana de Educación, 17, 105-187.

Nahmad, S. (1982) Indoamérica y Educación: ¿Etnocidio o Etnodesarrollo? En: Bonfil, G. et al. (1982) América Latina: Etnodesarrollo y Etnocidio. San José, FLACSO, 161-182

Palma, D. (1998) La Participación y la Construcción de Ciudadanía. Santiago, Centro de Investigaciones Sociales, Universidad ARCIS (Documento de trabajo №27).

Poblete, R. (2002) Educación Intercultural Bilingüe en Cerro Navia. Revista del Magíster en Políticas Sociales, Universidad Arcis. Cuadernos de Prácticas Sociales, 2, 151-179.

Supanta, A. (1995) La Ley Indígena y los Desafíos para Implementar una Educación Intercultural Bilingüe en Chile. En: MINEDUC-CONADI (1995) Calidad, Identidad, Diversidad: Conversaciones sobre Educación Intercultural Bilingüe en Chile. Temuco, MINEDUC-CONADI, 17-22.

Varese, E. (1982) Límites y Posibilidades del Desarrollo de las Etnias Indias en el Marco del Estado Nacional. En: Bonfil, G. et al. (1982) América Latina: Etnodesarrollo y Etnocidio. San José, FLACSO, 147-160. 